\title{
Emerging small molecule antivirals may fit neatly into COVID-19 treatment
}

\author{
Caroline Fenton $^{1} \cdot$ Susan J. Keam ${ }^{1}$ (1)
}

Accepted: 24 January 2022 / Published online: 28 February 2022

(c) Springer Nature Switzerland AG 2022

\begin{abstract}
Numerous treatments exist for COVID-19, the illness caused by SARS-CoV-2 virus, although most are not well established; among these are several small molecule antiviral agents. Intravenous remdesivir is an established treatment worldwide for inpatients and in some countries is also available for use in non-hospitalised high risk patients to prevent progression to severe disease and hospitalization. Oral molnupiravir and oral nirmatrelvir-ritonavir are also available in several countries to prevent progression to severe disease and hospitalization for high-risk outpatients. Many other antiviral small molecules that may have therapeutic potential are under investigation in clinical trials. This article provides a summary of key molecular targets, pharmacology and preliminary data on the efficacy and safety of small molecule antiviral agents being investigated for the treatment of COVID-19.
\end{abstract}

\section{Prevention better than COVID-19 cure}

Much has been learned in the months since the severe acute respiratory syndrome (SARS)-CoV-2 coronavirus, which causes COVID-19, overwhelmed an unprepared world; however, pharmacological treatment options are still very limited [1,2]. Despite the preferred preventative approach via vaccines, COVID-19 cases still abound [3]. Most cases are mild or asymptomatic, although still contagious [4]. For those more severely affected, COVID-19 treatment aims to reduce viral load and manage and dampen the overexuberant inflammatory response that causes the often fatal acute respiratory distress syndrome (ARDS) and myocarditis [1, 5].

Essential pharmacological treatment options include antiviral agents (to reduce viral load) as well as immunomodulators and biologics [2], particularly as it is the inflammatory response and release of proinflammatory cytokines

The manuscript was reviewed by: S.A. Antoniu, 'Grigore T. Popa' University of Medicine and Pharmacy, Department of Medicine II, Pulmonary Disease University Hospital, Iaşi, Romania; S. Mirkov, University of Otago School of Pharmacy, Dunedin, New Zealand; $\boldsymbol{A}$ Vitiello, USL Umbria 1 Pharmaceutical Department, Italy.

Susan J. Keam

dtp@adis.com

1 Springer Nature, Mairangi Bay, Private Bag 65901, Auckland 0754, New Zealand (the "cytokine storm" characteristic of ARDS) rather than SARS-CoV-2 infection per se that is fatal [5]. Of interest, some antiviral agents also act as immunomodulators $[1,6]$.

The COVID-19 treatment pipeline includes both "repurposed" agents already approved or developed for other indications and new compounds [1]. Benefits of the former include known adverse drug events and ready availability, but the efficacy of most in COVID-19 has been lacklustre $[2,7]$.

\section{Small molecules more accessible, if supply chain works}

In a pandemic setting, reliable bulk manufacture of pharmacological agents is vital; however, it is likely that supply chain issues will arise [8]. Both small molecules and biologics are being studied in COVID-19 [3]. Overall, small molecules tend to be more accessible than biologics due to stability, oral formulation and lower cost (Table 1) [8-10].

This article reviews emerging small molecule antiviral (according to WHO ATC code or EPhMRA code) COVID19 treatments up to mid-January 2022, with a focus on those furthest along the regulatory pathway. Discussion of the role of other small molecule classes, biologics and older immunomodulators like corticosteroids in the treatment of COVID-19 is outside the scope of this article. 
Table 1 Comparison of the properties of small molecules and biologics, as reviewed by Ledford [9] and Makurvet [8]

\begin{tabular}{|c|c|c|}
\hline Property & Small molecules & Biologics \\
\hline Typical size of molecule $(\mathrm{kDa})$ & $0.1-1.0$ & $>1.0$ \\
\hline \multirow[t]{2}{*}{ Manufacturing and logistics } & $\begin{array}{l}\text { Mostly fairly simple, with active ingredient manufac- } \\
\text { tured from chemical compounds }\end{array}$ & $\begin{array}{l}\text { Mostly complex, derived from living bacteria, yeasts, } \\
\text { mammalian tissues or cells, requiring cell cultures, } \\
\text { multiplication and manipulation }\end{array}$ \\
\hline & $\begin{array}{l}\text { Drug is stabilised and packaged in tablets or vials, } \\
\text { subject to supply chain issues }\end{array}$ & Less stable, although mAbs are an exception \\
\hline Formulation/administration & Normally oral & Normally IV, not orally available \\
\hline Able to cross BBB & Yes, if $<600 \mathrm{Da}$, can act on CNS & No \\
\hline Therapeutic targets & $\begin{array}{l}\text { Many intracellular and extracellular enzymes and } \\
\text { proteins, with specific inhibitors "nibs" }\end{array}$ & Specific parts of the immune system \\
\hline Drug interactions & Can be significant, due to renal or hepatic metabolism & $\begin{array}{l}\text { Relatively few, as they are metabolised much like } \\
\text { endogenous molecules and have more specific } \\
\text { targets }\end{array}$ \\
\hline ADEs & Not immunogenic & $\begin{array}{l}\text { Immunogenic, and rarely, but devastatingly, trigger } \\
\text { cytokine release }\end{array}$ \\
\hline Logistics & $\begin{array}{l}\text { More affordable and easily stored, usually easier to } \\
\text { mass manufacture }\end{array}$ & $\begin{array}{l}\text { Expensive, } \geq 22 x \text { small molecule cost, need refrigera- } \\
\text { tion }\end{array}$ \\
\hline \multirow[t]{3}{*}{ Examples } & $\begin{array}{l}\text { Antiviral agents: e.g. nucleoside analogues (remdesi- } \\
\text { vir, favipravir, molnupiravir) and protease inhibitors } \\
\text { (nirmatrelvir-ritonavir) }\end{array}$ & \multirow[t]{3}{*}{$\begin{array}{l}\text { Monoclonal antibodies: e.g. tocilizumab, casirivimab/ } \\
\text { imdevimab }\end{array}$} \\
\hline & $\begin{array}{l}\text { Tyrosine kinase inhibitors: e.g. baricitinib, bemcen- } \\
\text { tinib }\end{array}$ & \\
\hline & Other small molecules: e.g. nitazoxanide & \\
\hline
\end{tabular}

$A D E$ adverse drug event, $B B B$ blood-brain barrier, $C N S$ central nervous system, $I V$ intravenous, $(k) D a$ kilodaltons, $m A b s$ monoclonal antibodies

\section{Look at viral family resemblances and proteins...}

Applying decades of knowledge of other coronaviruses to identify relevant, readily available drugs is seen as the fastest way to develop potential SARS-CoV-2 therapeutics [1]. The need for speed, however, should not overwhelm the need for evidence of good efficacy and safety [11].

SARS-CoV-2 is a large-genome, enveloped, positivesense RNA virus of the genus Betacoronavirus and is closely related are SARS-CoV (for which SARS is named) and Middle East respiratory syndrome (MERS)-CoV [1, 12]. Both of these emerged in the twenty-first century to cause fatal human respiratory illness [1], but they mostly spread via nosocomial, not community, routes and pandemics were avoided [5]. SARS-CoV-2 also shares some features with unrelated viruses, e.g. HIV [13].

The SARS-CoV-2 genome codes for 4 structural proteins and 16 non-structural proteins (nsps [14]), all of which provide potential pharmaceutical antiviral targets (Table 2). Structural proteins are the three surface proteins [spike (S), membrane (M) and envelope (E)] and the two-domain, multifunctional nucleocapsid $(\mathrm{N})$ protein [14]. The S protein, which has a glycan shield of uncertain significance, has $\mathrm{S} 1$ and $\mathrm{S} 2$ subunits and has been closely studied during vaccine development. The $\mathrm{N}$ protein, involved in RNA binding, is needed for effective viral replication [14]. Recent $\mathrm{E}$ protein studies indicate that its ability to affect cell polarity may correlate with viral virulence. Nsps 3-16 are similar across most coronaviruses, but nsp1 is not [15]. Some SARS-CoV-2 structural and non-structural proteins have a high degree of sequence similarity to those of SARS-CoV and MERS-CoV [1].

\section{... and modify its lifecycle and immune effects}

Like other viruses, SARS-CoV-2 infects humans cells by taking over host cell functions ranging from cell entry (to effect viral replication and assembly) to release from host cells (Table 2, [1, 13]). Small molecule antiviral treatments targeting these processes are accordingly broadly grouped into viral entry, replication and release inhibitors (Tables 2 and 3) [1], although the last are so far largely experimental in SARS-CoV-2 [1].

Most treatment aims to prevent or treat severe COVID-19 in high-risk patients. These include people who are older, obese or pregnant, as well as those with cancer (especially leukaemia or lymphoma), diabetes, or respiratory, cardiovascular and other comorbidities [6].

Investigations show that cytokines that drive the most severe illness include interleukins (ILs) 2, 6, 7 and 8, tumour 
Table 2 SARS-CoV-2 infective life cycle and key small molecule pharmacological targets, as reviewed by Scudellari [13] and Laws [1]

\begin{tabular}{|c|c|c|}
\hline $\begin{array}{l}\text { Viral life stage and key } \\
\text { mediators }\end{array}$ & Key small molecule targets & Types: examples of small molecule antiviral therapies \\
\hline \multirow{3}{*}{$\begin{array}{l}\text { Viral entry via cell mem- } \\
\text { brane binding, fusion and } \\
\text { release of viral genome }\end{array}$} & Viral S protein & AXL kinase inhibitor: bemcentinib \\
\hline & Host ACE2, AXL receptors & Non-steroidal antiandrogen that $\downarrow$ TMPRSS $2+/$ - ACE2: proxalutamide ${ }^{\mathrm{a}}$ \\
\hline & $\begin{array}{l}\text { Host proteases: TMPRSS2, cathep- } \\
\sin \mathrm{L} \text {, furin }\end{array}$ & \\
\hline \multirow{6}{*}{$\begin{array}{l}\text { Viral replication and assem- } \\
\text { bly in the host cell }\end{array}$} & \multirow{3}{*}{$\begin{array}{l}\text { Host cell components, including } \\
\text { proteins, enzymes (e.g. eIF-2 } \alpha \\
\text { kinase, SK2) and cytoskeleton }\end{array}$} & CK2 inhibitor: silmitasertib \\
\hline & & $\uparrow$ eIF-2 $\alpha$ kinase phosphorylation: nitazoxanide SK inhibitor: opaganib ${ }^{a}$ \\
\hline & & $a-$ and $\beta$-tubulin inhibitor and cytoskeleton disruptor: sabizabulin \\
\hline & \multirow{3}{*}{ 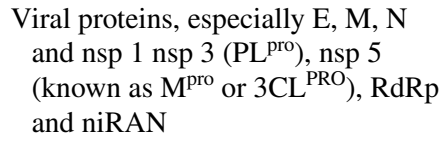 } & Protease $\left(3 \mathrm{CL}^{\mathrm{PRO}}\right)$ inhibitor: nirmatrelvir \\
\hline & & RdRp inhibitors: favipravir, remdesivir, molnupiravir \\
\hline & & niRAN antagonist: AT-527 \\
\hline \multirow[t]{2}{*}{ Viral exit from host cell } & Viral $\mathrm{S}$ and $\mathrm{E}$ proteins & None with significant development in COVID-19 \\
\hline & Host calcium-ion channel and furin & $\begin{array}{l}\text { Oseltamivir, a neuraminidase inhibitor for influenza, is an example and } \\
\text { used as control in some COVID-19 trials }\end{array}$ \\
\hline
\end{tabular}

$A C E 2$ angiotensin converting enzyme-2, $C K 2$ casein kinase 2, 3CL PRO 3 -chymotrypsin like protease, $E$ envelope, eIF-2 $\alpha$ eukaryotic initiation factor 2 alpha, $M$ membrane, $M^{p r o}$ main protease, $N$ nucleocapsid, $n i R A N$ nidovirus RdRp-associated nucleotidyltransferase, $n s p$ non-structural protein, $P L^{\text {pro }}$ papain-like protease, $R d R p$ RNA-dependent RNA polymerase $\mathrm{p}, S$ spike, $S K$ sphingosine kinase, TMPRSS 2 transmembrane protease serine $2, \downarrow$ decrease(s)/downregulates, $\uparrow$ increase(s)/upregulates

${ }^{\text {a }}$ Dual effect, also acts as host cell immunomodulator or anti-inflammatory

necrosis factor (TNF)- $a$ and interferon (INF)- $\gamma[5,6]$; for some of these cytokines, antagonists already exist [5]. Granulocyte-colony stimulating factor, INF- $\gamma$-inducible protein 10 , macrophage inflammatory protein $1-\alpha$ (MIP-1 $\alpha$ ), and monocyte chemoattractant protein-1 (MCP-1) are also of interest [5]. Clinical trials indicate that a low level of type 1 IFN is also a poor prognostic factor, as are elevated C-reactive protein and D-dimer levels $[5,16]$.

\section{Mutating genes, resistance and safety matter}

The potential for drug resistance, particularly for those to be used as monotherapy, needs to be considered when developing antivirals for the treatment of COVID-19. The propensity of SARS-CoV-2 for drug resistance is inversely proportional to its genetic stability [1]. Although its structural proteins are very stable [14], the mutations that do occur in the S1 subunit explain some of the increased infectivity of the a, $\delta$ and omicron SARS-CoV-2 variants [13, 17]. Despite this, experience with SARS-CoV suggests resistance may not be a significant problem for viral entry inhibitors [1]. Resistance is also less of an issue with agents that directly target host cell, rather than viral, factors (Table 2). These agents may, helpfully, also reduce ARDS via immune modulation (Table 2). Nevertheless, resistance to remdesivir (an RdRp inhibitor) has been reported after emergence of an E802D mutation during treatment of an immune-deficient patient with COVID-19 (Table 3) [18].

The choice of antiviral agent may depend on the potential for drug-drug interactions, particularly in patients who are being treated for underlying health issues and therefore may be at high risk of developing severe COVID-19 [19, 20]. Among the small molecule antivirals that are currently available for the treatment of COVID-19, nirmatrelvir-ritonavir [21-23] has numerous and complex drug-drug interactions (including with over-the-counter medicines and herbal supplements) because of the ritonavir component, which is required to achieve effective nirmatrelvir concentrations (Tables 3 and 4). For clinicians who are not experienced in prescribing ritonavir-boosted therapies, consultation with an expert should be considered [24]. In contrast, remdesivir [25, 26] and molnupiravir [27, 28] and their active metabolites do not inhibit or induce major drug metabolising enzymes and are not inhibitors of major drug transporters, so interaction with concomitant medications is unlikely (Tables 3 and 4).

\section{Don't gloss over gaps in pharmacology}

Pharmacological features of several approved or almostapproved COVID-19 therapies are still being elucidated (Table 3), with ideal dosages sometimes unclear [4, 29, 30]. Investigations into several repurposed antivirals, such as favipravir [4, 29, 30], suggest the plasma and lung concentrations needed to treat COVID-19 may be higher than 
Table 3 Pharmacological features of available small molecule antivirals with potential in COVID-19, as reviewed by Laws et al [1]

Parameter

Key information

Remdesivir (Veklury ${ }^{\circledR}$, Redyx $^{\text {TM }}$, GS-5734 ${ }^{\text {TM }}$, Captisol-enabled GS 5734/remdesivir); Gilead Sciences [25, 26]

Formulation

IV injection or infusion (available as either a $100 \mathrm{mg}$ lyophilized powder to be reconstituted as a 5 $\mathrm{mg} / \mathrm{mL}$ solution or a $100 \mathrm{mg} / 20 \mathrm{~mL}$ solution for dilution) [25, 26], other formulations including inhaled options being investigated [31]

Drug class/background Broad-spectrum nucleoside analogue effective against RNA viruses, studied in influenza, Ebola, MERS, Marburg and others

Mechanism of action

Pharmacological properties

$\downarrow$ viral replication by RdRp inhibition, via metabolite remdesivir triphosphate [25, 26]

$\mathrm{EC}_{50}=0.77 \mu \mathrm{M}, \mathrm{CC}_{50}>100 \mu \mathrm{M}, \mathrm{SI}>129.87$ in Vero cells, MOI 0.05 [33]. In vitro activity maintained against SARS-CoV-2 Omicron variant [34]. Several resistance mutations (NSP12 E802D and E802A mutants and NSP6 I168T mutant) identified in vitro [35]; an E802D mutation has emerged in a patient [18]

Absorbed and rapidly metabolised in humans; peak concentration of remdesivir and metabolites in $\leq 2 \mathrm{~h}$

Substrate for CYP3A4, metabolite 50\% excreted in urine [25, 26]

Inhaled formulations of remdesivir have aerosol characteristics consistent with good pulmonary delivery properties in vitro [36-38] and achieve effective pulmonary drug concentrations in animal models [36-38]. A phase $1 / 2$ study of inhaled remdesivir 31 or $62 \mathrm{mg}$ in early stage COVID-19 infection has completed (NCT04539262). A phase 1 study of an inhaled nanoparticle formulation of remdesivir in healthy volunteers is underway (NCT04480333)

Favipiravir (Avifavir $^{\circledR}$, Avigan $^{\circledR}$, FabiFlu $^{\circledR}$, Reeqonus ${ }^{\text {TM }}$, T705, T705a); Fujifilm Toyama Chemicals $[39,40]$

Formulation

Oral 200, 400 or $800 \mathrm{mg}$ tablets

Drug class/background

Pyrazinecarboxamide derivative and nucleoside analogue studied in Ebola, influenza and other viruses and originally approved in Japan for resistant influenza infections. Prodrug requiring phosphorylation in tissues to T-705-RTP, the active form of the drug

Mechanism of action

$\downarrow$ viral replication by RdRp inhibition, mutagenic in viral, but apparently not host cells [4, 41]

Pharmacological properties

In vitro SARS-CoV-2 $\mathrm{EC}_{50}=61.88 \mu \mathrm{M}, \mathrm{CC}_{50}>400 \mu \mathrm{M}$, SI $>6.46$, MOI 0.05 [42]

Complex pharmacokinetics; no clear correlation between favipiravir plasma concentrations and clinical efficacy [29]

Long half-life of active metabolite FAVI-RTP results in adequate intracellular levels despite fast clearance [30]

Molnupiravir (Lagavrio, MK-4482, EIDD-2801); Merck/Ridgeback Biotherapeutics [27, 28, 43]

Formulation Oral $200 \mathrm{mg}$ capsules

Drug class/background Prodrug of rNHC with broad antiviral activity, studied in Ebola, influenza, MERS and others [44]

Mechanism of action $\quad \downarrow$ viral replication by RdRp inhibition, via second metabolite NHC triphosphate that causes mutations during viral replication [41] and which, at high dosages, is also mutagenic to host cells [41]

Pharmacological properties $\quad \mathrm{EC}_{50} 0.32-2.03 \mu \mathrm{M}$ in Vero cells; $\mathrm{IC}_{50} 1.32-1.77 \mu \mathrm{M}$ [45]; NHC had similar activity against SARSCoV-2 variants B.1.1.7 (Alpha), B.1351 (Beta), P.1 (Gamma) and B.1.617.2 (Delta) [EC F0 $_{1.59}$, 1.77 and 1.32 and $1.68 \mu \mathrm{M}$, respectively] [43]; $\mathrm{CC}_{50}>20$ in Vero E6 cells [46]; MOI $\approx 0.1$ for key SARS-CoV-2 variants [44] In vitro activity maintained against SARS-CoV-2 Omicron variant [34]

Rapidly absorbed in humans and metabolised to NHC with linear dose-proportional pharmacokinetics, not plasma bound; minimal renal excretion (3\%) and likely minor hepatic excretion [27, 28, 43]

\section{Nirmatrelvir (PF-07321332)-ritonavir (PAXLOVID ${ }^{\text {TM}}$ ); Pfizer [21-23, 47-50]}

Formulation

Oral $150 \mathrm{mg}$ (nirmatrelvir) and $100 \mathrm{mg}$ (ritonavir) co-packaged tablets

Drug Class/background

Protease inhibitor. Coadministered with low-dose ritonavir to maintain effective nirmatrelvir plasma concentrations

Mechanism of action Viral replication inhibitor via $\downarrow$ viral 3CL ${ }^{\text {PRO }}$ protease [21-23, 47-50]

Pharmacological properties

$\mathrm{EC}_{50} 74.5 \mathrm{nM}$ in Vero cells with $\mathrm{EI}$ (to inhibit P-gp mediated efflux; $\mathrm{EC}_{50} 4.48 \mu \mathrm{M}$ with no EI); $\mathrm{EC}_{90}=317 \mathrm{nM}$ in cytopathic effect assays $\mathrm{CC}_{50}>100 \mu \mathrm{M}$, [47] In vitro activity maintained against SARS-CoV-2 variants of concern, including Omicron [34, 51, 52]

Phase 1 trial: drug exposure over $10 \mathrm{~d}$ at $5 \times$ the level predicted to inhibit SARS-CoV-2 viral replication [47]

Nirmatrelvir is a CYP3A4 substrate and is mainly eliminated via the kidneys. Coadministration with ritonavir slows metabolism of nirmatrelvir to achieve higher drug concentrations [22, 23] 
Table 3 (continued)

\begin{tabular}{|c|c|}
\hline Parameter & Key information \\
\hline \multicolumn{2}{|c|}{ Proxalutamide (GT-0918); Kintor Pharmaceuticals [53] } \\
\hline Formulation & Oral $200 \mathrm{mg}$ tablet or IV $300 \mathrm{mg}$ suspension (used in clinical trials) [53] \\
\hline Drug class/background & Anti-androgen being studied in metastatic breast and prostate cancer \\
\hline \multirow[t]{3}{*}{ Mechanism of action } & Viral entry/internalisation inhibitor and immune modulator [53] \\
\hline & $\begin{array}{l}\text { Inhibits androgen that moderates TMPfRSS2 protease in viral entry, possibly also moderates ACE2 } \\
\text { expression [53] }\end{array}$ \\
\hline & $\begin{array}{l}\text { Activates nuclear factor erythroid 2-related factor pathway, } \uparrow \text { pathogen clearance and } \downarrow \text { cytokine } \\
\text { response [53] }\end{array}$ \\
\hline Pharmacological properties & $\begin{array}{l}\text { Only studied in cancer patients. Rapid absorption, steady-state serum concentration of main metabo- } \\
\text { lite at d } 21 \text { [54] }\end{array}$ \\
\hline \multicolumn{2}{|c|}{ Nitazoxanide (NT-300); Romark Pharmaceuticals [55-57] } \\
\hline Formulation & Oral $500 \mathrm{mg}$ extended release tablets and $100 \mathrm{mg} / 5 \mathrm{~mL}$ suspension; should be taken with food \\
\hline Drug class/background & $\begin{array}{l}\text { Antiprotozoal agent that also has a broad spectrum antiviral activity studied in influenza and other } \\
\text { viruses; FDA-approved for some infectious diarrhoea in children aged } \geq 1 \text { year, adolescents and } \\
\text { adults }\end{array}$ \\
\hline \multirow[t]{2}{*}{ Mechanism of action } & $\begin{array}{l}\downarrow \text { viral replication and possibly immune modulation through a range of mechanisms: active metabo- } \\
\text { lite tizoxanide } \uparrow \text { host cell antiviral response, especially } \uparrow \text { interferon regulatory factor } 1[56]\end{array}$ \\
\hline & $\begin{array}{l}\downarrow \text { Spike protein maturation, blocking syncytia formation and may modulate mitochondrial function } \\
\text { and signalling pathways, to } \downarrow \text { host cell secretion of pro-inflammatory cytokines including interleu- } \\
\text { kin } 6 \text { [56] }\end{array}$ \\
\hline \multirow[t]{2}{*}{ Pharmacological properties } & $\begin{array}{l}\text { Absorbed and rapidly metabolised in humans to tizoxanide, then tizoxanide glucuronide in } \leq 4 \mathrm{~h} \text {, } \\
\text { peak concentration occurs in } \leq 4 \mathrm{~h} \text {; exposure with food } \uparrow 50 \% \text { for tablet and } 10 \% \text { for suspension }\end{array}$ \\
\hline & Highly plasma bound and excreted via faeces and urine, no significant CYP inhibition [55] \\
\hline
\end{tabular}

$A C E 2$ angiotensin converting enzyme-2, $C C_{50}$ half maximal cytotoxic concentration, $3 C L^{P R O}$ 3-chymotrypsin like protease, $C Y P$ cytochrome $\mathrm{P} 450, d$ days, $E C_{50}$ half maximal effective concentration, $E I$ efflux inhibitor, $F D A$ US Food \& Drug Administration, $I C_{50}$ half maximal inhibitory concentration, $I V$ intravenous, MERS Middle East respiratory syndrome, $M O I$ multiplicity of infection, $N H C$ N-hydroxycytidine, $P$ - $g p$ P-glycoprotein, $R d R p$ RNA-dependent RNA polymerase inhibitor p, SI selectivity index, TMPRSS2 transmembrane protease serine $2, \downarrow$ decrease(s), $\uparrow$ increase(s)

for influenza or HIV and perhaps closer to those required for Ebola treatment [4,29]. Inhaled formulations of drugs used to treat COVID-19 infection can deliver the drug directly to the site of activity, avoid first-pass metabolism and have less systemic toxicity, so may be of benefit [31]. Clinically, the best constant plasma drug concentration may be at least the identified in vitro $\mathrm{EC}_{90}$; combinations of antivirals are also often preferred [30].

From a safety perspective, the ideal antiviral has an effective or inhibitory trough concentration $\left(\mathrm{EC}_{50}\right.$ or $\left.\mathrm{IC}_{50}\right)$ well below the half-cytotoxic concentration $\left[\mathrm{CC}_{50}\right]$ (Table 3) [4] and will not cause serious adverse drug events at the highest clinically effective dose (Table 4). Both the in vitro selectivity index and, especially for oral agents that will be used mostly at home, the clinical therapeutic index [4] are important. At this stage, clinical results (Table 4) are driving many decisions $[11,32]$.

\section{Endpoints evolving in "learn-as-we-go" trials}

Currently, the most prominent small molecule antivirals in clinical use are remdesivir [58], which has full approval for COVID-19 treatment in a number of countries (Tables 3 and 4) and molnupiravir and nirmatrelvir-ritonavir, which have either conditional approval or are in the regulatory preregistration or emergency use authorisation (EUA) phase of approval (Tables 3 and 4) [20]. Along with dexamethasone, remdesivir is often now the "standard of care" (SOC) comparator in clinical trials (Table 4). Lopinavir/ritonavir or hydroxychloroquine were common early SOCs [59], but newer meta-analyses and reviews do not support their use in COVID-19 [60-62]

Aside from some doubtful SOCs, comparing different agents is complex, as primary endpoints vary and have evolved with emerging understanding of COVID-19 [68]. In early trials, virological cure, preferably measured with the reverse transcription polymerase chain reaction (RTPCR), was often the primary endpoint, but it was seldom achieved $[60,62]$. Clinical primary endpoints are now more 
Table 4 Preliminary data on efficacy and tolerability of small molecule antivirals approved/with EUA in COVID-19 and/or other indications

Parameter

Key information

Remdesivir (Veklury ${ }^{\circledR}$ Redyx $^{\mathrm{TM}}$ ), viral replication inhibitor approved in COVID-19 [25, 26, 63]

Recommended COVID-19 dosage (all IV)

USA [26, 63]: Adults and paediatric pts (aged $\geq 12 \mathrm{y}$ and $\geq 40 \mathrm{~kg}$ ): $200 \mathrm{mg} \mathrm{d} 1$ then $100 \mathrm{mg}$ for $\leq 4 \mathrm{~d}$ if not on $\mathrm{MV}$, or $\leq 9 \mathrm{~d}$ if on MV/no response or for $3 \mathrm{~d}$ in adults and paediatric pts $\geq 40 \mathrm{~kg}$ not requiring supplemental oxygen who are at increased risk of progressing to severe COVID-19; paediatric pts weighing 3.5 to $<40.0 \mathrm{~kg}: 5 \mathrm{mg} / \mathrm{kg} \mathrm{d} 1$ then $2.5 \mathrm{mg} / \mathrm{kg}$ for $\leq 4 \mathrm{~d}$ if not on $\mathrm{MV}$, or $\leq 9 \mathrm{~d}$ if on MV

EU [25]: Adults and adolescents $\geq 40 \mathrm{~kg}$ : $200 \mathrm{mg} \mathrm{d} 1$ then $100 \mathrm{mg}$ for $\geq 5 \mathrm{~d}$ but $<10 \mathrm{~d}$ if requiring supplemental oxygen or for $3 \mathrm{~d}$ in adults not requiring supplemental oxygen who are at increased risk of progressing to severe COVID-19 (treatment commenced as soon as possible and within $7 \mathrm{~d}$ of symptom onset)

COVID-19 approvals and EUAs

US approval for adults and paediatric pts (aged $\geq 12 \mathrm{y}$ and $\geq 40 \mathrm{~kg}$ ) with COVID-19 who are hospitalised or who are not hospitalized and have mild-to-moderate COVID-19, and are at high risk for progression to severe COVID-19, including hospitalization or death [26]; EUA for these indications in paediatric pts aged $<12 \mathrm{y}$ and $\geq 3.5 \mathrm{~kg}$ and in those aged $\geq 12 \mathrm{y}$ but weighing 3.5 to $<40.0 \mathrm{~kg}[63]$

EU approval for hospitalised adults and adolescents aged $>12 \mathrm{y}$ and in adults who do not require supplemental oxygen and who are at increased risk of progressing to severe COVID-19 [25]

Approval or EUAs in adults and adolescents aged $>12 \mathrm{y}$ and $\geq 40 \mathrm{~kg}$ in many other countries Efficacy in mild-moderate COVID-19 P3 PL-controlled trial (GS-US-540-9012; NCT04501952) using a 3 d course in mild-moderate COVID-19 in 562 symptomatic high-risk pts [64]

PE achieved: $\downarrow$ hospitalisation or death by d 28 with remdesivir vs PL $[0.7 \%$ vs $5.3 \%$ (HR 0.134 ; 95\% CI 0.031-0.586; $p=0.0076)$ ]; 0 deaths in either arm by d 28 [64]

Efficacy in other severity COVID-19 Moderate-severe COVID-19: P3 trials in 584 and 4891 pts achieved PE of improvement in clinical status vs SOC with remdesivir $5 \mathrm{~d}$ course, but no extra benefit from $10 \mathrm{~d}$ course $[65,66]$

Large WHO Solidarity trial [67] found no ACM benefit in hospitalised pts

Systematic review [61] and a meta-analysis [62] found improved hospital discharge times

Severe COVID-19: P3 (ACCT-1) trial in 1062 pts, $\approx 90 \%$ with severe COVID-19 [68] achieved PE of d 29 TTR: median $10 \mathrm{vs} 15 \mathrm{~d}$ with remdesivir for $\leq 10 \mathrm{~d}$ vs PL $(p<0.001)$; smaller trial found no benefit [69]

Adding bemcentinib improved median TTR (7 vs $8 \mathrm{~d}, p=0.03$ ) in a follow-on study [70] and the combination $\downarrow$ MV and improved discharge rates in a large meta-analysis [71]

Tolerability and safety

Mild-moderate ADEs: pyrexia, nausea and abnormal laboratory parameters including $\downarrow$ GFR, Hb and/or lymphocytes, $\uparrow$ creatinine and/or blood glucose, $\uparrow$ ALT, AST and prothrombin time in $\geq 5 \%$

Severe ADEs: seizure, rash, $\uparrow$ heart rate all $\leq 2 \%$ [26]

Precautions and drug interactions: monitor hepatic function for $\uparrow$ enzymes; coadministration with HCQ or chloroquine is not recommended due to cytochrome P450 3A4 metabolism [26]

Special pt populations: limited data suggests remdesivir safe in pregnancy and poor oral absorption may allow safe breastfeeding [26]

Not recommended if $\mathrm{ClCr}<30 \mathrm{~mL} / \mathrm{min}$ (adults and adolescents) [26] or $\mathrm{sCr} \geq 1 \mathrm{mg} / \mathrm{dL}$ in neonates aged $7 \mathrm{~d}$ to $\leq 28 \mathrm{~d}[63]$

Pending P3 COVID-19 trials Numerous studies recruiting or active, including NCT 04431453 pharmacokinetics in children [72]

Favipiravir (Avifavir ${ }^{\circledR}$, Avigan ${ }^{\circledR}$, FabiFlu ${ }^{\circledR}$, Reeqonus $^{\mathrm{TM}}$ ), viral replication inhibitor, approved in influenza

Recommended COVID-19 dosage $\quad 1800 \mathrm{mg}$ bid d 1 then $800 \mathrm{mg}$ bid for $\leq 13 \mathrm{~d}$ in recent trials [4]

(oral)

COVID-19 approvals and EUAs

New analysis suggests $1600 \mathrm{mg}$ d 1 then $800 \mathrm{mg} \times 3 \mathrm{~d}$ or $1200 \mathrm{mg} \times 9 \mathrm{~d}$ may be effective [73]

Efficacy in mild-moderate COVID-19

Approved in Russia; EUA in Latin America, India and Asia [74] for mild-severe COVID-19

P3 trial composite PE including VC was not achieved, but meta-analysis found a $\mathrm{d} 7$ and weaker $\mathrm{d}$ $14 \mathrm{VC}$ benefit [75], as did another trial [76] and a large $(n=940)$ retrospective review [74]

Consistent benefit in time to $\downarrow$ fever vs PL or SOC (e.g. HCQ, lopinavir/ritonavir) [59, 76, 77]

Varied chest imaging, oxygen saturations, and cough results in clinical trials and reviews [59, 61, 77]

Efficacy in other severity COVID-19 Asymptomatic and other mild COVID-19: $\downarrow$ CRP in recurrent cases, tendency to better VC [78, 79] Moderately severe-critical COVID-19: no clear benefit vs HCQ [80] 
Table 4 (continued)

Parameter

Tolerability and safety
Key information

Mild-moderate ADEs: diarrhoea, pyrexia, nausea $(<5 \%)[59,75,79]$ and abnormal laboratory parameters including hyperuricaemia, $\uparrow$ blood uric acid (30-40\%) $\uparrow$ ALT, triglycerides $(\leq 15 \%)$, AST, hepatic function $(5-10 \%) \uparrow$ neutrophils $[59,75,79]$

Serious, possibly drug-related ADEs: cardiac arrest, cerebral infarction, liver disorder, pneumonia [39]

Precautions and drug interactions: gout and hyperuricaemia, coadministration with pyrazinamide, repaglinide, theophylline, sulindac [39]

Contraindications: pregnancy and breastfeeding although no mutagenic effects detected in vitro [79]

Pending P3 COVID-19 trials

Four completed, no results posted: NCT04349241, NCT04981379, NCT04303299, NCT04351295

19 others in progress

Molnupiravir (Lagevrio), viral replication inhibitor [27, 28, 43]

Recommended COVID-19 dosage (oral)

COVID-19 approvals and EUAs

$800 \mathrm{mg}$ bid $\times 5 \mathrm{~d}$, as soon as possible and within $5 \mathrm{~d}$ of symptom onset

Conditional approval in the UK [27] and EUA in the EU [43] and in the USA [28] for mild-tomoderate COVID-19 in adult pts who are at risk of developing severe COVID-19; seeking EUAs elsewhere

Efficacy in mild-moderate COVID-19 P3 component of the P2/3 MOVe-OUT PL-controlled trial $(n=1433)$ in mild-moderate COVID-19 in symptomatic high-risk pts [81]

PE achieved: $\downarrow$ hospitalisation or all-cause death through day 29 with molnupiravir vs PL [interim analysis $(n=762) 7.3 \%$ vs $14.1 \%$; $p=0.0012$; final analysis $(n=1408) 6.8 \%$ vs $9.7 \%$ ]; 1 molnupiravir- and 9 PL-group COVID-19-related deaths through d 29 [81]. Results confirmed those of the $\mathrm{P} 2$ component in 302 pts [82]

Efficacy in other severity COVID-19 MOVe-OUT subgroup analysis in 40\% of pts showed efficacy against $\gamma, \delta$, and $\mu$ variants [44]

$\mathrm{P} 2$ component of the P2/3 MOVe-IN ( $n=304)$ showed that in pts hospitalized with COVID-19 molnupiravir 200-800 $\mathrm{mg}$ bid for 5 d provided no clinical benefit vs PL [83]

Tolerability and safety causing withdrawal from trial [84]

Precautions and drug interactions: reproductive toxicity in animals, no drug interactions predicted $[27,28,43]$

Contraindications: pregnancy and breastfeeding. Not authorized for use in pts aged $<18$ y because MOL may affect bone and cartilage growth [27, 28, 43]

Special pt populations: no dose adjustment in kidney or liver impairment [27, 28, 43]

Pending P3 COVID-19 trial NCT04939428 (MOVe-AHEAD) PE: non-infection in adults living with someone with COVID-19 Nirmatrelvir (PF-07321332)-ritonavir (PAXLOVID ${ }^{\text {TM}}$ ) protease inhibitor [21-23]

Recommended COVID-19 dosage (oral)

COVID-19 approvals and EUAs

Efficacy in mild high-risk COVID-19

Efficacy in standard-risk COVID-19
$300 \mathrm{mg}+100 \mathrm{mg}$ bid for $5 \mathrm{~d}$ as soon as possible and within $5 \mathrm{~d}$ of symptom onset

Conditional approval in the UK [22] and the EU [21] and EUA in the USA [23] in pts with mild-tomoderate COVID-19 at risk of progression to severe COVID-19. Seeking EUAs in other countries

PE met in P 2/3 EPIC-HR trial in non-hospitalized pts with high risk of progressing to severe COVID-19 in interim analysis $(n=780)$ [89.1\% reduction in risk of hospitalization or death with nirmatrelvir-ritonavir vs PL when administered within $3 \mathrm{~d}$ of symptom onset $(0.8 \%$ vs $7 \%$; $p<0.0001)$ ] significant reduction in risk vs PL when administered within $5 \mathrm{~d}$ of symptom onset as well $(p<0.0001)$. No deaths through d 28 nirmatrelvir-ritonavir arm vs 10 deaths in PL arm $[21-23,50]$. Final analysis $(n=2246)$ confirmed $89 \%$ reduction in risk of hospitalization or death vs PL when administered within $3 \mathrm{~d}$ of symptom onset $(0.7 \%$ vs $6.5 \% ; p<0.0001)$. No deaths through d 28 in nirmatrelvir-ritonavir arm vs 12 deaths in PL arm [50]

PE (self-reported, sustained alleviation of symptoms for 4 consecutive $\mathrm{d}$ with nirmatrelvir-ritonavir vs PL) not met in interim analysis of EPIC-SR (at $45 \%$ of planned enrolment). $0.6 \%$ vs $2.4 \%$ of pts were hospitalized (no deaths in either treatment arm) [50] 
Table 4 (continued)

Parameter

Tolerability and safety

Pending P2/3 COVID-19 trials

Key information

TEAEs mostly mild and comparable to PL (19\% vs $21 \%$ ); few SAEs (1.7\% vs $6.6 \%)$ and treatment discontinuations due to AEs (2.1\% vs $4.1 \%$ ) [50]

Precautions and drug interactions: hepatotoxicity, potential for developing resistance to HIV protease inhibitors in pts with uncontrolled/undiagnosed HIV-1 infection. Numerous drug interactions identified (because of coadministration with ritonavir, which is predominantly metabolized by CYP3A) [21-23]

Contraindications: co-administration with drugs highly dependent on CYP3A for clearance where high levels of those drugs are associated with serious/life-threatening ADEs; coadministration with drugs that are potent CYP3A inducers and therefore reduce plasma levels of nirmatrelvir or ritonavir, which may lead to loss of virological response and the potential for drug resistance [21-23]

Special pt populations: dose reductions in moderate kidney impairment; not recommended in severe kidney or liver impairment [21-23]

NCT05047601 (EPIC-PEP) P2/3 nirmatrelvir-ritonavir bid $\times 5 / 10$ d, PE: post-exposure prophylaxis in household contacts of symptomatic COVID-19 case;

NCT05011513 (EPIC-SR) final results. P2/3 mild COVID-19, low-risk pts, nirmatrelvir-ritonavir bid $\times 5 \mathrm{~d}$, PE: TTR

\section{Proxalutamide (GT-0918), viral replication inhibitor and immune modulator}

COVID-19 dosage used in trials (oral/ IV)

COVID-19 approvals and EUAs

Efficacy in mild-moderate COVID-19

Efficacy in other severity COVID-19
Mild-moderate oral $200 \mathrm{mg}$ od or bid; in severe or critically ill patients oral or IV 300mg od

EUA in Paraguay for hospitalised pts [85]

Statistical significance not achieved in interim analysis of P3 trial (NCT04870606) in non-hospitalized pts with mild COVID-19 $(n=348)$ who received proxalutamide $200 \mathrm{mg}$ or PL bid within $5 \mathrm{~d}$ of symptom onset for $14 \mathrm{~d}$ [53]

P3 trial in 645 hospitalised pts (North arm; NCT04728802) receiving proxalutamide $300 \mathrm{mg} / \mathrm{d}$ vs PL [86]

PE: d 14 TTR achieved, 81\% vs 36\% with proxalutamide vs PL [RR 2.28 (95\% CI 1.95-2.66); $p<$ $0.001]$

28 d ACM $11 \%$ vs 49\%, [RR 0.16 (95\% CI 0.11-0.24], 77\% lower with proxalutamide vs PL [86]

Combined data from North (NCT04728802) and South (NCT05126628) arm trials $(n=778)$ : $\mathrm{d} 14$ TTR $81.1 \%$ vs $36.6 \%$ [RR 2.21 (95\% CI 1.92-2.56); $p<0.0001$ ] 28 d ACM $10.6 \%$ vs $48.2 \%$ [RR 0.22 (95\% CI 0.16-0.30); $p<0.001]$ [87]

Tolerability and safety

Pending P3 COVID-19 trials

Mild ADEs: diarrhoea (15-20\%), abdominal pain, irritability, spontaneous erection $(<5 \%)$

Severe ADEs $\leq 3 \%$ proxalutamide vs $5-41 \%$ PL recipients (notably shock and MV) [86, 87]

NCT04853927 in critically ill pts, PE: ACM; NCT05009732 in hospitalised pts, PE: TTR
NCT05009732 in hospitalized pts. PE: TTR

NCT04853134 outpatient study in mild-moderate COVID-19, PE: non-hospitalisation

NCT04869228 outpatient study in mild-moderate COVID-19, PE: change to clinical status d 11 and oxygen need d 28

\begin{tabular}{|c|c|}
\hline \multicolumn{2}{|c|}{ Nitazoxanide (Alinia ${ }^{\circledR}$ and many others), viral replication inhibitor $+/-$ immune modulator approved as antiparasitic agent } \\
\hline $\begin{array}{l}\text { Recommended COVID-19 dosage } \\
\text { (oral) }\end{array}$ & $300 \mathrm{mg}$ bid for $5 \mathrm{~d}$, potential prophylaxis dosage $600 \mathrm{mg}$ bid for $6 \mathrm{wks}$ [72] \\
\hline COVID-19 approvals and EUAs & Seeking FDA EUA [57] \\
\hline \multirow[t]{2}{*}{ Efficacy in mild-moderate COVID-19 } & PL-controlled trial in 1092 symptomatic people aged $\geq 12$ y \\
\hline & PE: time to sustained response with nitazoxanide not achieved vs PL [57] \\
\hline \multirow[t]{3}{*}{ Efficacy in other severity COVID-19 } & Mild COVID-19 subgroup ( $n=247)$ had faster sustained response (10 vs 13 d) \\
\hline & $\begin{array}{l}85 \% \downarrow(0.5 \% \text { with nitazoxanide vs } 3.6 \% \text { with PL) in progression to severe disease including high- } \\
\text { risk pts }(0.9 \% \text { vs } 5.6 \%)\end{array}$ \\
\hline & Large network meta-analysis [62] found improved VC [OR $1.72(1.20,2.73)][57]$ \\
\hline
\end{tabular}


Table 4 (continued)

\begin{tabular}{ll}
\hline Parameter & Key information \\
\hline Tolerability and safety & $\begin{array}{l}\text { Mild ADEs: diarrhoea }(<5 \%)[57] \\
\text { Precautions and contraindications: may compete with other highly plasma bound agents, e.g. war- } \\
\text { farin }\end{array}$ \\
$\begin{array}{l}\text { Special pt populations: approved in pts aged }>1 \text { y for Giardia lamblia and Cryptosporidium parvum } \\
\text { diarrhoea }\end{array}$ & $\begin{array}{l}\text { No studies in kidney or hepatic impairment or other special populations [55] } \\
\text { NCT04359680: PE: non-infection in high-risk groups, e.g. healthcare, after nitazoxanide } 600 \text { mg } \\
\text { bid } \times 6 \text { wks }\end{array}$ \\
\hline Pending P3 COVID-19 trial &
\end{tabular}

Patients were eligible for SOC, usually dexamethasone and/or remdesivir in hospitalised pts, as well as specified trial interventions

$A C M$ all-cause mortality, $A D E$ adverse drug event, $A E$ adverse event, $A L T$ alanine aminotransferase, $A S T$ aspartate aminotransferase, bid twice daily, $(s) C r$ (serum) creatinine, $C r C l \mathrm{Cr}$ clearance, $C R P$ C-reactive protein, $d$ day(s), EMA European Medicines Agency, EUA emergency use authorisation, $F D A$ US Food \& Drug Administration, $H C Q$ hydroxychloroquine, $H R$ hazard ratio, $h s C R P$ high-sensitivity CRP, $I V$ intravenous, $M V$ mechanical ventilation, $O R$ odds ratio, $P 2, P 3$, phase 2, 3, $P E$ primary endpoint, $P L$ placebo, $p t(s)$ patient(s), $R R$ risk ratio, $S A E$ serious adverse event, SOC standard of care, TEAE treatment-emergent adverse event, TTR time to recovery, $V C$ viral clearance/cure, $w k(s)$ week(s), $y$ year(s), $\downarrow$ decrease(d), $\uparrow$ increase(d)

common (Table 4) and these may change during a trial (e.g. to day 29 from the original day 15 primary endpoint in the remdesivir ACCT-1 trial in severe disease [68]). Recent disappointments (e.g. for AT-527 [88] and eicosapentaenoic acid [7]) have resulted in a further rethink and/or a focus on narrower patient subgroups [89]. Drug dosages used in the treatment of patients with COVID-19 have also come under the spotlight $[73,90]$.

Newer COVID-19 studies are also taking place against a changing patient backdrop. Better understanding of COVID-19's clinical course and consequent treatment protocols have contributed to significantly improved patient outcomes since the pandemic started [2, 91]. Between March 2020 and April 2021, COVID-19 mortality rates in selected US hospitals decreased from approximately $18 \%$ to $4 \%$ and length of stay from 12 to 7 days [92]. In-hospital patient demographics have also changed, with one US study reporting mild disease in almost half of those diagnosed with COVID-19 in early 2021, versus $36 \%$ during 2020 [93].

In terms of patient selection, criteria for mild, moderate and severe disease range from $\mathrm{WHO}$ and other ordinal scales to oxygen saturations $\left(\mathrm{SpO}_{2} \%\right)$ and/or clinical descriptions $[68,69,80]$. As far as possible, disease severity in Table 4 is based on outpatient or hospital status and $\mathrm{SpO}_{2}$ as follows:

- mild: non-hospitalised and sometimes asymptomatic, $\mathrm{SpO}_{2} \geq 95 \%$;
- moderate: hospitalised but not needing active COVID-19 therapy or oxygen, $\mathrm{SpO}_{2} \geq 94 \%$;

- moderate-severe: hospitalised, on supplemental oxygen but not mechanical ventilation, $\mathrm{SpO}_{2} \geq 93 \%$; or

- severe-critical: requiring mechanical ventilation, $\mathrm{SpO}_{2}<$ $93 \%$.

Two network meta-analyses [60, 62], which enable comparisons in the absence of head-to-head trials, assessed all-cause mortality, virological cure [60, 62], mechanical ventilation, hospital discharge and/or adverse drug events in 46 [60] and 222 [62] randomised, controlled trials reported in peer reviewed journals. Proxalutamide, nitazoxanide and remdesivir (Tables 3 and 4) improved some outcomes, as did the combination of remdesivir and baricitinib [60, 62].

\section{A multitude of studies, but relatively few results}

Hundreds of small molecule COVID-19 therapy studies are underway [1], with some preliminary efficacy and tolerability data now available (Table 5) and a range of registered trials in progress (Tables 4, 5 and 6). 
Table 5 Early trial results for emerging small molecule antivirals in phase 2/3 or 3 trials in adults for treatment of COVID-19. Drugs are oral formulations, unless specified. Standard of care in most hospitalised patients is now remdesivir and/or dexamethasone

Parameter Key information

Bemcentinib (BGB 324, BGB3234, R428) [with FDA fast track status for cancer]

Mechanism of action Viral entry/internalisation inhibitor, antikinase immune modulator

Inhibits AXL tyrosine kinase receptor and $\uparrow$ anti-viral IFN response [94]

Efficacy and tolerability Mild-moderate COVID-19: PE of better survival, TTR and TTW not significant with bemcentinib $400 \mathrm{mg} \times 1 \mathrm{~d}$ then $200 \mathrm{mg} \times \leq 14 \mathrm{~d}$ vs SOC in P2 trials $(n=177)$ [94]

In pt subgroup with more severe COVID-19 and BL C-reactive protein $\geq 30 \mathrm{mg} / \mathrm{mL}$ ( $60 \%$ of pts): TTW better with bemcentinib than SOC [94]

ADEs: diarrhoea, headache, pulmonary embolism and $\uparrow$ ALT, hyperglycaemia $(\leq 5 \%)$

Serious ADEs: cardiovascular events, $\uparrow$ ALT, septic shock + acute renal failure caused treatment discontinuation [94]

Ongoing COVID-19 trials None, although trial in more severe pts contemplated [95]

Opaganib (ABC 294640, YELIVA) [being investigated for cancer]

Mechanism of action Sphingosine kinase-2 inhibitor with dual viral replication inhibition and anti-inflammatory properties; $\downarrow$ levels of IL-6 and TNF-alpha in bronchoalveolar lavage fluids [96]

Efficacy and tolerability Moderate COVID-19: minor benefit with opaganib vs PL for oxygen needs in small P2a trial

Severe COVID-19: PE of d 14 room air not significant for opaganib vs PL in P2/3 trial $(n=465)$; post hoc analysis in moderately severe COVID-19 $(n=251)$ showed d 14 room air achieved in $77 \%$ opaganib vs $64 \%$ PL recipients $(p=0.033), 62 \% \downarrow$ ACM, and $\downarrow$ TT discharge (14 vs $10 \mathrm{~d}$ ) [both $p=0.02]$ [96]

Ongoing COVID-19 trials None

Sabizabulin (Vero-111) [being investigated for cancer]

Mechanism of action

Viral replication inhibitor and immune modulator, via $\alpha$ - and $\beta$-tubulin $\downarrow$ and cytoskeleton disruption that $\downarrow$ viral intracellular transport and $\alpha$ - and $\beta$-tubulin colchicine site binding, $\downarrow$ microtubule polymerisation and inflammation [97]

Efficacy and tolerability

Moderate-severe COVID-19: PE of $\downarrow$ ACM/respiratory failure not significant with sabizabulin 18 mg od $\times 21$ d despite $81 \% \downarrow(5.6 \%$ sabizabulin vs $30 \%$ PL) in P2 trial in hospitalised high-risk pts with COVID-19 $(n=38) ;) ; \downarrow$ ACM/respiratory failure significant pts aged $>60$ y (9\% vs $50 \%)$ and severe COVID-19 (11\% vs 54\%) and in ICU d [98]

Ongoing COVID-19 trials P3 NCT04842747 in 300 severe +/- high-risk hospitalised pts, 21 d sabizabulin vs PL, PE: ACM d 60

AT-527 (Drug R07496998) [prodrug of guanosine nucleotide developed for Hepatitis C]

Mechanism of action

Viral replication inhibitor, primarily targets viral polymerase nidovirus RdRp-associated nucleotidyltransferase function [99] to $\downarrow$ viral RNA synthesis, active metabolite AT-511 [100]

Efficacy and tolerability

Mild-moderate COVID-19: PE of $\downarrow$ d 7 viral load not achieved in P2 MOONSONG trial with AT-527 550 or $1100 \mathrm{mg}$ bid vs PL; possible benefit in high-risk subgroup may lead to change in MORNINGSKY trial design [61]

ADEs: in $20 \%$ pts, mostly gastrointestinal (5-10\%), no clinically significant laboratory abnormalities [88]

Ongoing COVID-19 trials

P3 NCT04889040 (MORNINGSKY) in mild-moderate COVID-19; AT527 $550 \mathrm{mg}$ bid $\times 5 \mathrm{~d}$ vs PL; PE: $\mathrm{d} 29$ TTR or TT symptomatic improvement

Observational NCT05059080 (MEADOWSPRING) 6-mo study assessing prior AT-527 in long COVID

\begin{tabular}{|c|c|}
\hline \multicolumn{2}{|c|}{ Auxora (CM 4260 Calcimedia); injectable emulsion given as IV infusion } \\
\hline Mechanism of action & $\begin{array}{l}\text { Immune modulator, selective inhibitor of CRAC channel, } \downarrow \text { epithelial and endothelial cell injury } \\
\text { and inflammation in lungs and other organs, } \downarrow \text { proinflammatory cytokine release [101] }\end{array}$ \\
\hline \multirow[t]{2}{*}{ Efficacy and tolerability } & $\begin{array}{l}\text { Severe-critical COVID-19: trial stopped at } 27 \mathrm{pts} \text {, to move to blinded trial: MV with Auxora in } 18 \% \\
\text { vs } 50 \% \text { with SOC, and D-dimer levels }-0.24 \mathrm{vs}+0.63 \mu \mathrm{g} / \mathrm{mL}\end{array}$ \\
\hline & Serious ADEs in $30 \%$ vs $50 \%, 2$ deaths in each $[16,101]$ \\
\hline Ongoing COVID-19 trials & $\begin{array}{l}\text { P2 NCT04345614 severe COVID-19 completed, no results, PE (revised): } \mathrm{d} \text { to recovery from start } \\
\text { of infusion of Auxora } 2.0 \mathrm{mg} / \mathrm{kg} \text { at } 0 \mathrm{~h} \text {, then } 1.6 \mathrm{mg} / \mathrm{kg} \text { at } 24 \mathrm{~h} \text { and } 1.6 \mathrm{mg} / \mathrm{kg} \text { at } 48 \mathrm{~h} \text { vs PL, both } \\
+ \text { SOC }\end{array}$ \\
\hline
\end{tabular}


Table 5 (continued)

Parameter Key information
Vidofludimus calcium (IMU-838) [being investigated in Crohn's disease, multiple sclerosis and others]
Mechanism of action Viral replication inhibitor and selective antikinase immune modulator, which inhibits dihydrooro- tate dehydrogenase and $\downarrow$ release of cytokines such as IL 17A, 17F and INF-y [3]
Efficacy and tolerability
Ongoing COVID-19 trials
Severe COVID-19: PE and SE not met as MV required in so few pts in P2 CALVID-1[91]
IMU-838 loading dose then $22.5 \mathrm{mg}$ bid + oseltamivir $75 \mathrm{mg}$ bid vs oseltamivir + SOC $\times 14 \mathrm{~d}$
Silmitasertib (CX-4945) [being investigated in cancer]
Mechanism of action Immune modulator, via casein kinase 2 inhibition [102]
Efficacy and tolerability Mild-moderate COVID-19: faster TT symptomatic recovery $(6 \mathrm{vs} 14 \mathrm{~d} ; p<0.02)$ with silmitasertib $1 \mathrm{~g}$ bid vs SOC, trend to faster improvement in health-related quality of life and normalisation of COVID signs in $\mathrm{P} 2$ trial $(n=20)$ [102]
Ongoing COVID-19 trials NCT04668209 P2/3, high-risk hospitalised pts; silmitasertib $\times 21$ d; PE: ADEs, SE: clinical effi- cacy

\begin{tabular}{ll}
\hline Abivertinib (abivertinib maleate, avitinib, AC0010, STI-5656) [originally investigated in cancer] \\
\hline Mechanism of action & Immune modulator, via epidermal growth factor receptor TK and Bruton's TK inhibition [103] \\
\hline Efficacy and tolerability & $\begin{array}{c}\text { Moderate-severe COVID-19: PE } \downarrow \text { treatment failure (ACM or respiratory failure) to d 28 achieved } \\
\text { in most severe subgroup }(\approx 20 \% \text { pts) in P2 trials in } 480 \text { hospitalised pts receiving abivertinib 200 } \\
\text { mg od for } \leq 28 \mathrm{~d} \text { or until discharge [103] }\end{array}$ \\
\hline Ongoing COVID-19 trials & None registered, P3 study in severe COVID-19 planned
\end{tabular}

Brilacidin (PMX-30063); given as IV infusion [being investigated in skin and soft tissue infections, oral stomatitis, inflammatory bowel disease]

Mechanism of action Virus internalisation inhibitor and immunomodulatory (non-peptidic HDP mimic); targets both viral proteins and host factors $[104,105]$

Efficacy and tolerability

Moderate-severe COVID-19: PE of TT sustained recovery through d 29 not met in top line analysis of data from P2 trial $(n=120)$ of brilacidin or PL for 3-5 d plus SOC. Generally well tolerated [106]

Ongoing COVID-19 trials

None registered. Ongoing analysis of data to see if eligible for inclusion in larger COVID-19 platform trials [107]; compassionate use program data in critically ill patients to be analysed [108]

$A C M$ all-cause mortality, $A D E$ adverse drug event, bid twice daily, $B L$ baseline, $C R A C$ calcium release-activated calcium, $d$ day(s), $H D P$ Host Defence Proteins/Peptides, $I L$ interleukin(s), $I N F$ interferon, $I V$ intravenous, $o d$ once daily, $P 2,2 / 3$ phase 2, 2/3, $P E$ primary endpoint, $p t(s)$ patient(s), $R d R p$ RNA-dependent RNA polymerase inhibitor, $S E$ secondary endpoint, $S O C$ standard of care, $T K$ tyrosine kinase, $T N F$ tumour necrosis factor, TT time to, TTR TT recovery, TTW TT worsening, $y$ years, $\downarrow$ decrease(s), $\uparrow$ increase(s)

\section{Table 6 Small molecule antivirals with phase 2 or 2/3 COVID-19 trials in progress and/or not yet reported [72]}

\begin{tabular}{lll}
\hline Agent & Company developing & Trials in progress (including phase) \\
\hline $\begin{array}{l}\text { Trials completed at 31 December 2021, but clinical results not yet reported } \\
\text { Antroquinonol }\end{array}$ & Golden Biotechnology & P2 NCT04523181 \\
\hline Asapiprant/BGE-175 & BioAge Labs & P2 NCT04705597 \\
\hline Brequinar & Clear Creek Bio & P1/2 NCT04425252 (CRISIS) \\
& & P2 NCT04575038 (CRISIS2) \\
\hline Trials in progress at 31 December 2021 & & \\
\hline ADX 629 & Aldeyra Therapeutics & P2 NCT04847544 \\
\hline ATR 002 & Atriva Therapeutics & P2 NCT04776044 \\
\hline Emvododstat (PTC 299) & PTC Therapeutics & P2/3 NCT 04439071, FITE19 \\
\hline GNS 561 & Genoscience Pharma & P2 NCT04637828, NCT04333914 \\
\hline MP 1032 & MetrioPharm AG & P2 NCT04932941, not yet recruiting \\
\hline Pentarlandir ${ }^{\text {TM }}$ UPPTA (SNB 011) & SyneuRx International (Taiwan) & P2 NCT04911777 \\
\hline Piclidenoson & Can-Fite Biopharma & P2 NCT04333472 \\
\hline Tafenoquine (Arakoda) & 60 Degrees Pharmaceuticals & P2 NCT04533347 \\
\hline Tempol (MBM-02) & Adamis Pharmaceuticals & P2/3 NCT04729595 \\
\hline Upamostat & Red Hill Biopharma & P2/3 NCT04723537 RHB-107-01 \\
\hline
\end{tabular}




\section{Take home messages}

- Three small molecule antivirals, intravenous remdesivir, oral molnupiravir and oral nirmatrelvir-ritonavir are among the available COVID-19 treatments; other small molecule antivirals and immune modulators are urgently needed.

- Small molecule antiviral therapies are practical pandemic options, as they are usually more easily manufactured, stable, orally available, less costly and may be repurposed from studies or use in viruses other that COVID19 , especially those closely related to SARS-CoV-2.

- While COVID-19 treatments are a pressing need, approved medications should meet high efficacy and safety standards and there are many gaps in current knowledge.

- Many small molecule antivirals show some promise in selected groups of COVID-19 patients, but large, randomised efficacy and safety studies of both monotherapy and combined antiviral agents are needed.

- New small molecule antivirals have been designed with a high barrier for drug resistance; real-world data are required to confirm this. Combination therapy using small molecule antivirals with different mechanisms of action may be required to overcome drug resistance in the future.

- Other administration routes for small molecule antivirals, including via inhalation, are a possibility.

\section{Declarations}

Funding The preparation of this review was not supported by any external funding.

\begin{abstract}
Authorship and conflict of interest C Fenton, a contracted employee of Adis International Ltd/Springer Nature, and S Keam, a salaried employee of Adis International Ltd/Springer Nature, declare no relevant conflicts of interest. All authors contributed to the review and are responsible for the article content.
\end{abstract}

Ethics approval, Consent to participate, Consent for publication, Availability of data and material, Code availability Not applicable.

\section{References}

1. Laws M, Surani YM, Hasan MM, et al. Current trends and future approaches in small-molecule therapeutics for COVID-19. Curr Med Chem. 2021;28(19):3803-24.

2. National Institutes of Health. Coronavirus Disease 2019 (COVID-19) treatment guidelines. 2021. https://www.covid19tre atmentguidelines.nih.gov/. Accessed 5 Nov 2021.

3. Stanford Medicine. Race to a cure. 2021. https://racetoacure.stanf ord.edu/. Accessed 5 Nov 2021
4. Joshi S, Parkar J, Ansari A, et al. Role of favipiravir in the treatment of COVID-19. Int J Infect Dis. 2021;102:501-8.

5. Pillaiyar T, Wendt LL, Manickam M, et al. The recent outbreaks of human coronaviruses: a medicinal chemistry perspective. Med Res Rev. 2021;41(1):72-135.

6. Aldea M, Michot JM, Danlos FX, et al. Repurposing of anticancer drugs expands possibilities for antiviral and anti-inflammatory discovery in Covid-19. Cancer Discov. 2021;11(6):1336-44.

7. Diaz R. PREPARE-IT 2: icosapent ethyl versus placebo in outpatients with Covid-19: the main results of PREPARE-IT 2 [abstract no. LBS.06]. In: \#AHA21. 2021.

8. Makurvet FD. Biologics vs. small molecules: drug costs and patient access. Med Drug Discov. 2021;9:1075.

9. Ledford H. Dozens of coronavirus drugs are in developmentwhat happens next? Nature. 2020;581(7808):247-8.

10. Nuventra. Points to consider in drug development of biologics and small molecules. 2020. https://www.nuventra.com/resou rces/blog/small-molecules-versus-biologics/. Accessed 4 Nov 2021.

11. Sidebottom DB, Smith DD, Gill D. Safety and efficacy of antivirals against SARS-CoV-2. BMJ. 2021;375:n2611.

12. Coronaviridae Study Group of the International Committee on Taxonomy of Viruses. The species Severe acute respiratory syndrome-related coronavirus: classifying 2019-nCoV and naming it SARS-CoV-2. Nat Microbiol. 2020;5(4):536-44.

13. Scudellari M. How the coronavirus infects cells-and why Delta is so dangerous. Nature. 2021;595(7869):640-4.

14. Troyano-Hernaez P, Reinosa R, Holguin A. Evolution of SARS-CoV-2 envelope, membrane, nucleocapsid, and spike structural proteins from the beginning of the pandemic to September 2020: a global and regional approach by epidemiological week. Viruses. 2021;13(2):243.

15. Khan MT, Irfan M, Ahsan H, et al. Structures of SARS-CoV-2 RNA-binding proteins and therapeutic targets. Intervirology. 2021;64(2):55-68.

16. Bruen C, Miller J, Schnaus M, et al. Auxora improves D-dimer levels in patients with severe COVID-19 pneumonia. Crit Care Med. 2021;49(1 Suppl.):134.

17. Syed AM, Ciling A, Khalid MM, et al. Omicron mutations enhance infectivity and reduce antibody neutralization of SARS-CoV-2 virus-like particles. medRxiv. 2022. https://doi. org/10.1101/2021.12.20.21268048.

18. Gandhi S, Klein J, Robertson A, et al. De novo emergence of a remdesivir resistance mutation during treatment of persistent SARS-CoV-2 infection in an immunocompromised patient: a case report. medRxiv. 2021. https://doi.org/10.1101/2021.11. 08.21266069 .

19. Centers for Disease Control and Prevention. Underlying medical conditions associated with higher risk for severe COVID19: information for healthcare providers. 2021. https://www. cdc.gov/coronavirus/2019-ncov/hcp/clinical-care/underlying conditions.html. Accessed 18 Jan 2022.

20. Burki TK. The role of antiviral treatment in the COVID-19 pandemic. Lancet. 2022. https://doi.org/10.1016/S2213-2600(22) 00011-X.

21. European Medicines Agency. Paxlovid: EU summary of product characteristics. 2022. https://www.ema.europa.eu/en. Accessed 8 Feb 2022.

22. Medicines \& Healthcare products Regulatory Agency. Paxlovid: summary of product characteristics. 2021. https://www.gov. uk/government/publications/regulatory-approval-of-paxlovid/ summary-of-product-characteristics-for-paxlovid. Accessed 11 Jan 2022.

23. US Food and Drug Administration. Fact sheet for healthcare providers: emergency use authorization for PAXLOVID ${ }^{\mathrm{TM}} .2021$. 
https://www.fda.gov/media/155050/download. Accessed 11 Jan 2022.

24. National Institutes of Health. The COVID-19 Treatment Guidelines Panel's statement on potential drug-drug interactions between ritonavir-boosted nirmatrelvir (Paxlovid) and concomitant medications. 2021. https://www.covid19treatmentguidelines. nih.gov/therapies/statement-on-paxlovid-drug-drug-interactions/. Accessed 18 Jan 2022

25. European Medicines Agency. Remdesivir (Veklury): EU summary of product characteristics. 2021. https://www.ema.europa. eu/. Accessed 20 Dec 2021.

26. Gilead Sciences Inc. VEKLURY-remdesivir injection: US prescribing information. 2020. https://www.veklury.com/. Accessed 17 Jan 2022.

27. Medicines and Healthcare products Regulatory Agency. Regulatory approval of Lagevrio (molnupiravir). 2021. https://www. gov.uk/government/publications/regulatory-approval-of-lagev rio-molnupiravir. Accessed 21 Dec 2021.

28. Merck. Fact sheet for healthcare providers: emergency use authorization for molnupiravir. 2021. https://www.merck.com/ eua/molnupiravir-hcp-fact-sheet.pdf. Accessed 21 Feb 2022.

29. Ison MG, Scheetz MH. Understanding the pharmacokinetics of favipiravir: implications for treatment of influenza and COVID19. EBioMedicine. 2021;63:103204.

30. Pertinez H, Rajoli RKR, Khoo SH, et al. Pharmacokinetic modelling to estimate intracellular favipiravir ribofuranosyl5'-triphosphate exposure to support posology for SARS-CoV-2. J Antimicrob Chemother. 2021;76(8):2121-8.

31. Eedara BB, Alabsi W, Encinas-Basurto D, et al. Inhalation delivery for the treatment and prevention of COVID-19 infection. Pharmaceutics. 2021;13(7):1077.

32. Zhao M, Zhang J, Li H, et al. Recent progress of antiviral therapy for coronavirus disease 2019. Eur J Pharmacol. 2021;890:173646.

33. Wang M, Cao R, Zhang L, et al. Remdesivir and chloroquine effectively inhibit the recently emerged novel coronavirus (2019$\mathrm{nCoV}$ ) in vitro. Cell Res. 2020;30(3):269-71.

34. Rosales R, McGovern BL, Rodriguez ML, et al. Nirmatrelvir, molnupiravir, and remdesivir maintain potent in vitro activity against the SARS-CoV-2 Omicron variant. bioRxiv. 2022. https://doi.org/10.1101/2022.01.17.476685.

35. Szemiel AM, Merits A, Orton RJ, et al. In vitro selection of remdesivir resistance suggests evolutionary predictability of SARS-CoV-2. PLoS Pathog. 2021;17(9):e1009929.

36. Vartak R, Patil SM, Saraswat A, et al. Aerosolized nanoliposomal carrier of remdesivir: an effective alternative for COVID-19 treatment in vitro. Nanomedicine (Lond). 2021;16(14):1187-202.

37. Li J, Zhang K, Wu D, et al. Liposomal remdesivir inhalation solution for targeted lung delivery as a novel therapeutic approach for COVID-19. Asian J Pharm Sci. 2021;16(6):772-83.

38. Sahakijpijarn S, Moon C, Koleng JJ, et al. Development of remdesivir as a dry powder for inhalation by thin film freezing. Pharmaceutics. 2020;12(11):1002.

39. Fujifilm Toyama Chemical Co. Ltd. AVIGAN tablets 200mg: prescribing information. 2014. https://www.cdc.gov.tw/File/Get/ ht8jUiB_MI-aKnlwstwzvw. Accessed 17 Jan 2022.

40. Glenmark Pharmaceuticals Limited. Unlocking the treatment for mild to moderate Covid-19 in India [media release]. 20 Jun 2020. https://www.glenmarkpharma.com/sites/default/files/GlenmarkFabiFlu-Press-Brief.pdf.

41. Zhou S, Hill CS, Sarkar S, et al. beta-d-N4-hydroxycytidine inhibits SARS-CoV-2 through lethal mutagenesis but is also mutagenic to mammalian cells. J Infect Dis. 2021;224(3):415-9.

42. Wang Y, Zhong W, Salam A, et al. Phase 2a, open-label, doseescalating, multi-center pharmacokinetic study of favipiravir
(T-705) in combination with oseltamivir in patients with severe influenza. EBioMedicine. 2020;62(103125).

43. European Medicines Agency. Molnupiravir (Lagevrio): EU emergency use approval. 2021. https://www.ema.europa.eu/en/ documents/referral/lagevrio-also-known-molnupiravir-mk-4482covid-19-article-53-procedure-conditions-use-conditions_en.pdf. Accessed 21 Dec 2021.

44. Grobler J, Strizki J, Murgolo N, et al. Molnupiravir maintains antiviral activity against SARS-CoV-2 variants in vitro and in early clinical studies [abstract no. 543 and poster]. Open Forum Infect Dis. 2021;8(Suppl):S373.

45. Medicines and Healthcare products Regulatory Authority. First oral antiviral for COVID-19, Lagevrio (molnupiravir), approved by MHRA [media release]. 4 Nov 2021. https://www.gov.uk/ government/news/first-oral-antiviral-for-covid-19-lagevriomolnupiravir-approved-by-mhra.

46. European Medicines Agency. Assessment report: use of molnupiravir for the treatment of COVID-19. 2021. https://www. ema.europa.eu/. Accessed 18 Jan 2022.

47. Owen DR, Allerton CMN, Anderson AS, et al. An oral SARSCoV-2 M(pro) inhibitor clinical candidate for the treatment of COVID-19. Science. 2021. https://doi.org/10.1126/science.abl47 84.

48. Pfizer Inc. Pfizer's novel COVID-19 oral antiviral treatment candidate reduced risk of hospitalization or death by $89 \%$ in interim analysis of phase 2/3 EPIC-HR study [media release]. 5 Nov 2021. https://www.pfizer.com/.

49. Pfizer Inc. Pfizer reports second-quarter 2021 results [media release]. 4 July 2021. https://s21.q4cdn.com/317678438/files/ doc_financials/2021/q2/Q2-2021-PFE-Earnings-Release.pdf.

50. Pfizer Inc. Pfizer announces additional phase $2 / 3$ study results confirming robust efficacy of novel COVID-19 oral antiviral treatment candidate in reducing risk of hospitalization or death [media release]. 14 Dec 2021. https://www.pfizer.com/.

51. Greasley SE, Noell S, Plotnikova O, et al. Structural basis for nirmatrelvir in vitro efficacy against the Omicron variant of SARS-CoV-2. bioRxiv. 2022. https://doi.org/10.1101/2022.01. 17.476556.

52. Rai DK, Yurgelonis I, McMonagle P, et al. Nirmatrelvir, an orally active Mpro inhibitor, is a potent inhibitor of SARS-CoV-2 variants of concern. bioRxiv. 2022:2022.01.17.476644.

53. Kintor Pharmaceutical Limited. Kintor Pharma provides update on one of its three multi-regional phase 3 trials of proxalutamide for COVID-19 [media release]. 27 Dec 2021. https://en.kintor. com.cn/.

54. Li H, Ran R, Jiang H, et al. Evaluation of safety, pharmacokinetics and pharmacodynamics of proxalutamide (GTO918), a potent androgen receptor (AR) blocker, in patients with metastatic brest cancer (mBC): phase 1 dose escalation trial [abstract no. P2-1705]. Cancer Res. 2020;80(4 Suppl).

55. Romark Pharmaceuticals. Alinia (nitazoxanide) oral tablets and suspension: US prescribing information. 2005. https://www. accessdata.fda.gov/drugsatfda_docs/label/2005/021818lbl.pdf. Accessed 5 Nov 2021.

56. Romark Pharmaceuticals. Romark initiates phase 3 clinical trials of NT-300 for COVID-19 [media release]. 27 April 2020. https:// www.romark.com/.

57. Romark Pharmaceuticals. Romark announces initial results of phase 3 clinical trial of NT-300 tablets for the treatment of COVID-19 [media release]. 14 Apr 2021. https://www.romark. $\mathrm{com} /$.

58. Vitiello A, Troiano V, La Porta R. What will be the role of molnupiravir in the treatment of COVID-19 infection? Drugs Ther Perspect. 2021;37(12):579-80.

59. Shinkai M, Tsushima K, Tanaka S, et al. Efficacy and safety of favipiravir in moderate COVID-19 pneumonia patients without 
oxygen therapy: a randomized, phase III clinical trial. Infect Dis Ther. 2021;10(4):2489-509.

60. Cheng Q, Chen J, Jia Q, et al. Efficacy and safety of current medications for treating severe and non-severe COVID-19 patients: an updated network meta-analysis of randomized placebo-controlled trials. Aging (Milano). 2021;13:1-37.

61. Gil Martinez V, Avedillo Salas A, Santander BS. Antiviral therapeutic approaches for SARS-CoV-2 infection: a systematic review. Pharmaceuticals (Basel). 2021;14(8):736.

62. Zhang C, Jin H, Wen YF, et al. Efficacy of COVID-19 treatments: a Bayesian network meta-analysis of randomized controlled trials. Front Public Health. 2021;9:729559.

63. Gilead Sciences. Fact sheet for health care providers emergency use authorization (EUA) oF VEKLURY® (remdesivir). 2022. https://www.gilead.com/remdesivir. Accessed 25 Jan 2022.

64. Gottlieb RL, Vaca CE, Paredes R, et al. Early remdesivir to prevent progression to severe Covid-19 in outpatients. N Engl J Med. 2021. https://doi.org/10.1056/NEJMoa2116846.

65. Goldman JD, Lye DCB, Hui DS, et al. Remdesivir for 5 or 10 days in patients with severe Covid-19. N Engl J Med. 2020;383(19):1827-37.

66. Spinner CD, Gottlieb RL, Criner GJ, et al. Effect of remdesivir vs standard care on clinical status at 11 days in patients with moderate COVID-19: a randomized clinical trial. JAMA. 2020;324(11):1048-57.

67. Pan H, Peto R, Henao-Restrepo AM, et al. Repurposed antiviral drugs for COVID-19-interim WHO Solidarity trial results. N Engl J Med. 2021;384(6):497-511.

68. Beigel JH, Tomashek KM, Dodd LE, et al. Remdesivir for the treatment of Covid-19-final report. N Engl J Med. 2020;383(19):1813-26.

69. Wang Y, Zhang D, Du G, et al. Remdesivir in adults with severe COVID-19: a randomised, double-blind, placebo-controlled, multicentre trial. Lancet. 2020;395(10236):1569-78.

70. Kalil AC, Patterson TF, Mehta AK, et al. Baricitinib plus remdesivir for hospitalized adults with COVID-19. N Engl J Med. 2021;384(9):795-807.

71. Zhang D, Du G, Du R, et al. Remdesivir in adults with severe COVID-19: a randomised, double-blind, placebo-controlled, multicentre trial. The Lancet. 2020;395(10236):1569-78.

72. US National Library of Medicine. ClinicalTrials.gov. 2022. https://clinicaltrials.gov/. Accessed 17 Jan 2022.

73. Pertinez H, Rajoli RK, Khoo SH, et al. Pharmacokinetic modelling to estimate intracellular favipiravir ribofuranosyl-5'-triphosphate exposure to support posology for SARS-CoV-2. medRxiv. 2021.

74. Corritori S, Yakubova E, Ivashchenko A, et al. Multicenter, openlabeled efficacy study of avifavir in patients with COVID-19. Top Antivir Med. 2021;29(1):138.

75. Manabe T, Kambayashi D, Akatsu H, et al. Favipiravir for the treatment of patients with COVID-19: a systematic review and meta-analysis. BMC Infect Dis. 2021;21(1):489.

76. Ivashchenko AA, Dmitriev KA, Vostokova NV, et al. Avifavir for treatment of patients with moderate Coronavirus Disease 2019 (COVID-19): interim results of a phase II/III multicenter randomized clinical trial. Clin Infect Dis. 2021;73(3):531-4.

77. Chen C, Huang J, Yin P, et al. Favipiravir versus arbidol for clinical recovery rate in moderate and severe adult COVID-19 patients: a prospective, multicenter, open-label, randomized controlled clinical trial. Front Pharmacol. 2021;12(683296).

78. Doi Y, Hibino M, Hase R, et al. A prospective, randomized, open-label trial of early versus late favipiravir therapy in hospitalized patients with COVID-19. Antimicrob Agents Chemother. 2020. https://doi.org/10.1128/aac.01897-20.

79. Zhao H, Zhang C, Zhu Q, et al. Favipiravir in the treatment of patients with SARS-CoV-2 RNA recurrent positive after discharge: a multicenter, open-label, randomized trial. Int Immunopharmacol. 2021;97:107702.

80. Khamis F, Al Naabi H, Al Lawati A, et al. Randomized controlled open label trial on the use of favipiravir combined with inhaled interferon beta-1b in hospitalized patients with moderate to severe COVID-19 pneumonia. Int J Infect Dis. 2021;102:538-43.

81. Jayk Bernal A, Gomes da Silva MM, Musungaie DB, et al. Molnupiravir for oral treatment of COVID-19 in nonhospitalized patients. N Engl J Med. 2021.

82. Caraco Y, Crofoot GE, Moncada PA, et al. Phase $2 / 3$ trial of molnupiravir for treatment of Covid-19 in nonhospitalized adults. NEJM Evidence. 2021. https://doi.org/10.1056/EVIDoa2100043.

83. Arribas JR, Bhagani S, Lobo SM, et al. Randomized trial of molnupiravir or placebo in patients hospitalized with Covid-19. NEJM Evid. 2021. https://doi.org/10.1056/EVIDoa2100044.

84. Painter WP, Holman W, Bush JA, et al. Human safety, tolerability, and pharmacokinetics of molnupiravir, a novel broadspectrum oral antiviral agent with activity against SARS-CoV-2. Antimicrob Agents Chemother. 2021;65(5):e02428-e2520.

85. Kintor Pharmaceutical Limited. Kintor Pharmaceutical receives emergency use authorization for proxalutamide for the treatment of COVID-19 in Paraguay [media release]. 16 July 2021. https:// en.kintor.com.cn/.

86. Cadegiani FA, do Nascimento Fonseca D, McCoy J, et al. Efficacy of proxalutamide in hospitalized COVID-19 patients: a randomized, double-blind, placebo-controlled, parallel-design clinical trial. medRxiv. 2021. https://doi.org/10.1101/2021.06. 22.21259318 .

87. Cadegiani FA, Zimerman RA, Fonseca DN, et al. Final results of a randomized, placebo-controlled, two-arm, parallel clinical trial of proxalutamide for hospitalized COVID-19 patients: a multiregional, joint analysis of the Proxa-Rescue AndroCoV trial. Cureus. 2021;13(12):e20691.

88. Atea Pharmaceuticals. Atea Pharmaceuticals provides update and topline results for phase 2 MOONSONG trial evaluating AT-527 in the outpatient setting [media release]. 19 Oct 2021. https://ir. ateapharma.com/news-releases/news-release-details/atea-pharm aceuticals-provides-update-and-topline-results-phase-2.

89. Amarin Corporation. Amarin reports overview of latest clinical research evaluating VASCEPA ${ }^{\circledR} /$ VAZKEPA (icosapent ethyl) and eicosapentaenoic acid (EPA) presented at ESC Congress 2021, organized by the European Society of Cardiology [media release]. 31 Aug 2021. https://investor.amarincorp.com/newsreleases/news-release-details/amarin-reports-overview-latestclinical-research-evaluating.

90. Rajoli RKR, Pertinez H, Arshad U, et al. Dose prediction for repurposing nitazoxanide in SARS-CoV-2 treatment or chemoprophylaxis. Br J Clin Pharmacol. 2021;87(4):2078-88.

91. Immunic Inc. Immunic, Inc. announces that oral treatment IMU838 shows evidence of clinical activity in moderate COVID-19 in phase 2 CALVID-1 trial [media release]. 17 Feb 2021. https:// imux.com/

92. National Center for Health Statistics. In-hospital mortality among hospital confirmed COVID-19 encounters by week from selected hospitals. 2021. https://www.cdc.gov/nchs/covid19/nhcs/hospi tal-mortality-by-week.htm. Accessed 5 Nov 2021.

93. David Sweig for the Atlantic Monthly. Our most reliable pandemic number is losing meaning. 2021. https://www.theatlantic. com/health/archive/2021/09/covid-hospitalization-numbers-canbe-misleading/620062/. Accessed 5 Nov 2021.

94. Wilkinson T, Gausdal G, McCracken N, et al. Bemcentinib, an oral AXL kinase inhibitor, results in lower mortality compared to standard of care (steroids with or without remdesivir) in hospitalised patients with COVID-19. Two randomised phase 2 studies: BGBC020 and ACCORD2. Online presentation at 31st ECCMID. 2021. https://www.bergenbio.com/wp-content/uploa 
ds/2021/07/ECCMID-2021-LB-oral-Bemcentinib-12jul2021-. pdf. Accessed 17 Jan 2022.

95. BerGenBio. BerGenBio announces top line data from phase III trial assessing bemcentinib in hospitalised Covid-19 patients [media release]. 18 May 2021. https://www.bergenbio.com/.

96. RedHill Biopharma. RedHill Biopharma reports further analysis of phase $2 / 3$ data including a $62 \%$ reduction in mortality with oral opaganib in moderately severe COVID-19 patients [media release]. 4 Oct 2021. https://www.redhillbio.com/.

97. Veru Pharma. Sabizabulin for COVID-19: (VERU-111). 2021. https://verupharma.com/pipeline/sabizabulin-for-covid-19/. Accessed 5 Nov 2021.

98. Veru Pharma. Veru reports positive phase 2 clinical results of VERU-111 in hospitalized COVID-19 patients at high risk for acute respiratory distress syndrome [media release]. 8 Feb 2021. https://verupharma.com/.

99. Zhou XJ, Horga A, Morelli G, et al. High lung levels of active triphosphate predicted with oral AT-527 in COVID patients [abstract no. 364]. Top Antivir Med. 2021;29(1):127.

100. Good SS, Westover J, Jung KH, et al. AT-527, a double prodrug of a guanosine nucleotide analog, is a potent inhibitor of SARS-CoV-2 in vitro and a promising oral antiviral for treatment of COVID-19. Antimicrob Agents Chemother. 2021;65(4):e02479-e2520.

101. Miller J, Bruen C, Schnaus M, et al. Auxora versus standard of care for the treatment of severe or critical COVID-19 pneumonia: results from a randomized controlled trial. Crit Care. 2020;24(1):502.

102. Senhwa Biosciences. Senhwa presents positive initial data from phase 2 clinical trial of silmitasertib (CX-4945) in moderate
COVID-19 patients at the ISIRV-WHO conference [media release]. 20 Oct 2021. https://www.senhwabio.com/.

103. Sorrento Therapeutics. Sorrento announces encouraging results from two phase 2 studies of abivertinib for treatment of hospitalized severe COVID-19 patients [media release]. 27 Oct 2021. https://investors.sorrentotherapeutics.com/.

104. Bakovic A, Risner K, Bhalla N, et al. Brilacidin, a COVID-19 drug candidate, exhibits potent in vitro antiviral activity against SARS-CoV-2. bioRxiv. 2020. https://doi.org/10.1101/2020.10. 29.352450

105. Hu Y, Jo H, DeGrado WF, et al. Brilacidin, a COVID-19 drug candidate, demonstrates broad-spectrum antiviral activity against human coronaviruses OC43, 229E and NL63 through targeting both the virus and the host cell. bioRxiv. 2021. https://doi.org/ 10.1101/2021.11.04.467344.

106. Innovation Pharmaceuticals. Innovation Pharmaceuticals announces topline results from phase 2 clinical trial of brilacidin for COVID-19 [media release]. Nov 11 2021. http://www.iphar minc.com/.

107. Innovation Pharmaceuticals. Innovation Pharmaceuticals conducting full data analysis of phase 2 brilacidin COVID-19 trial results to support brilacidin's potential inclusion in governmentsponsored COVID-19 trials [media release]. Nov 12 2021. http:// www.ipharminc.com/.

108. Innovation Pharmaceuticals. Innovation Pharmaceuticals analyzing full dataset for its brilacidin COVID-19 clinical trial; company evaluating new pipeline opportunities for 2022 [media release]. Dec 7 2021. http://www.ipharminc.com/. 